\title{
The Influence of Climate on Foliar Symptoms of Eutypa Dieback in Grapevines
}

\author{
M. R. Sosnowski, D. Shtienberg, M. L. Creaser, T. J. Wicks, R. Lardner, and E. S. Scott
}

First, third, and fourth authors: South Australian Research and Development Institute, GPO Box 397, Adelaide, SA, 5001 Australia; second author: Department of Plant Pathology, ARO, the Volcani Center, Bet Dagan, 50250, Israel; and fifth and sixth authors: School of Agriculture, Food and Wine, The University of Adelaide, Waite Campus, Glen Osmond, SA, 5064 Australia.

Current address of R. Lardner: CSIRO Entomology, PMB 2, Glen Osmond, SA, 5064 Australia.

Accepted for publication 10 April 2007.

\begin{abstract}
Sosnowski, M. R., Shtienberg, D., Creaser, M. L., Wicks, T. J., Lardner, R., and Scott, E. S. 2007. The Influence of climate on foliar symptoms of Eutypa dieback in grapevines. Phytopathology 97:1284-1289.

Foliar symptoms of Eutypa dieback, caused by Eutypa lata, in grapevines, cv. Shiraz, varied from year to year in a 6-year study conducted in South Australia and, although trends were similar for vineyards within geographical regions, differences were observed between regions. We attempted to elucidate the causes underlying this variation and hypothe-

18 months earlier, (ii) decreased disease incidence and prevalence were related to increased temperature in spring, and (iii) a reduction in disease incidence was related to both very high and very low rainfall in October. Theories for these relationships are proposed and require further investigation. A conceptual model was developed which requires validation and has the potential to predict the incidence of foliar symptoms of Eutypa dieback. Information from this study could lead to an improved integrated pest management system to suppress foliar symptoms and sustain productivity of vines infected with $E$. lata.
\end{abstract} sized that it was influenced by climatic factors. A number of possible relationships were identified between climate and symptom expression: (i) increased symptom expression was related to increased winter rainfall
Additional keywords: Vitis vinifera.
Eutypa dieback, caused by the ascomycete Eutypa lata (Pers.) Tul. \& C. Tul (= E. armeniacae Hansf. \& M.V. Carter), affects grapevines (Vitis vinifera L.) in many regions of the world (6). It contributes to vineyard decline by reducing growth and yield $(8,14)$ and, ultimately, kills infected vines. In South Australia, Eutypa dieback has been estimated to cause yield losses of at least 860 and $740 \mathrm{~kg} / \mathrm{ha}$ for Shiraz and Cabernet Sauvignon, respectively (23) and, in California, economic losses of up to US\$260 million per annum have been attributed to the disease (19).

Ascospores of E. lata produced in perithecia on wood that has been killed by the pathogen are released after rain (3). A minimum rainfall of 1 or $2 \mathrm{~mm}$ is required for ascospore release from apricot and grapevine wood, respectively $(11,18,22)$. Ascospores, which are dispersed by wind, enter grapevines through fresh pruning wounds and germinate in xylem vessels, after which the fungus colonizes the wood $(4,12)$. Wood symptoms include internal necrosis, visualized as wedge-shaped areas of stained tissue on cross-sections of the external cankers that form around sites of infection in the trunks or cordons (13).

Foliar symptoms, comprising stunted shoots with chlorotic leaves, often cupped and with tattered margins, are thought to be caused by toxic metabolites produced by the fungus in the wood and transported to the foliage (13,21). However, Mahoney et al. (10) suggested that fungal metabolites may interact with the wood at the point of production, disrupting vascular structure and inhibiting nutrient transport, thereby inducing foliar symptoms. More recently, it was found that the expression of foliar symp-

Corresponding author: M. R. Sosnowski;

E-mail address: Sosnowski.mark@ saugov.sa.gov.au

doi:10.1094/PHYTO-97-10-1284

(C) 2007 The American Phytopathological Society toms was not directly related to wood infection (20). Symptoms are expressed 3 to 8 years after infection $(5,21)$.

Carter (6) documented the influence of the environment on ascospore production. Furthermore, optimal conditions for germination and growth of E. lata in vitro are 20 to $25^{\circ} \mathrm{C}$ and at least $90 \%$ relative humidity $(1,3)$. Susceptibility of grapevine wounds to infection is generally favored by cool winter conditions $(7,15)$. The expression of foliar symptoms of Eutypa dieback has been reported to fluctuate markedly from year to year in Australia, France, and North America $(2,8,9)$, but to be consistent over years and vineyards in Spain (16). Little is known about the environmental influences on the initial stages of infection and growth of E. lata in vivo, or on the expression of foliar symptoms.

We hypothesize that climatic factors, affecting both the host and the pathogen, influence the expression of foliar symptoms of Eutypa dieback and are responsible for annual fluctuations in symptom severity. An increased understanding of these factors could facilitate development of improved strategies for disease management. Thus, the objectives of this study were to (i) quantify the relationships between climatic factors and the expression of foliar symptoms and (ii) formulate a conceptual model of Eutypa dieback epidemiology to be used as a framework for constructing improved management strategies for Eutypa dieback.

\section{MATERIALS AND METHODS}

Field sites and climate data collection. Five vineyards (cv. Shiraz) in the Eden Valley (EV) and Coonawarra (C) regions of South Australia were assessed annually for foliar symptoms of Eutypa dieback. The Eden Valley (latitude $34^{\circ} 35^{\prime} \mathrm{S}$, longitude $139^{\circ} 00^{\prime} \mathrm{E}$, and elevation 200 to $400 \mathrm{~m}$ ) and Coonawarra (latitude $37^{\circ} 18^{\prime} \mathrm{S}$, longitude $140^{\circ} 50^{\prime} \mathrm{E}$, and elevation $60 \mathrm{~m}$ ) regions are approximately $350 \mathrm{~km}$ apart and have mean annual rainfall of 500 and $650 \mathrm{~mm}$, respectively. All vines were own-rooted and grown 
using a vertical trellis system. Vineyards EV1 and EV2, planted in 1971, were drip irrigated and were mechanically prepruned in June or July and then hand pruned in August or early September. Vineyard C1, planted in 1970, was not irrigated until 2002, when a drip system was installed. The vines were machine pruned in June or July followed by hand pruning in mid- to late August. Vineyard C2, planted in 1968, was irrigated by overhead sprinklers until 1996, when a drip system was installed. The vines were minimally hand pruned in June or July until 1996, after which they were mechanically prepruned, followed by hand pruning in June or July. Vineyard C3, planted in 1968, was irrigated by overhead sprinklers. Originally cane pruned, from 1985 vines were mechanically prepruned in September, immediately followed by hand pruning. Pruning was performed as recommended in commercial vineyards in the respective regions and was not specifically directed at removing branches exhibiting symptoms of Eutypa dieback.

Automatic weather stations were used to collect climate data. At Eden Valley, an on-site weather station was located within 1 $\mathrm{km}$ of each trial site at $34^{\circ} 38^{\prime} 22^{\prime \prime} \mathrm{S}, 139^{\circ} 02^{\prime} 44^{\prime \prime} \mathrm{E}$. The automatic weather station comprised software and housing designed by Measurement Engineering Australia (Adelaide, Australia), and a tipping bucket rain gauge (Hydrological Services, Sydney, Australia) and temperature sensor (Vaisala, Helsinki, Finland). At Coonawarra, the Bureau of Meteorology weather station was located at $37^{\circ} 29^{\prime} 06^{\prime \prime} \mathrm{S}, 140^{\circ} 82^{\prime} 54^{\prime \prime} \mathrm{E}$, which was within $5 \mathrm{~km}$ of each trial site. The automatic weather station comprised software and housing designed by Almos Systems (Perth, Australia), and a tipping bucket rain gauge (Rimco-McVan Instruments, Melbourne, Australia) and temperature sensor (Rosemount, Chanhassen, MN). Maximum, minimum, and average daily temperatures and daily rainfall were recorded at both sites.

Disease assessment. In each vineyard, a block of vines was selected randomly and symptoms assessed each spring (midNovember for Eden Valley, early December for Coonawarra) when symptomless shoots were 50 to $100 \mathrm{~cm}$ long. In each vineyard, the same vines were assessed for between 3 and 6 consecutive years from 1999 to 2004 . The number of vines assessed and the years of assessment in each vineyard were as follows: vineyard EV1, 144 vines, 2000-04; vineyard EV2, 110 vines, 2001-04; vineyard C1, 144 vines, 2000-02; vineyard C2, 126 vines, 1999-2002; and vineyard C3, 115 vines, 1999-2004. Each vine was assessed visually as a mean of all spur positions as follows: (i) the proportion of vine canopy exhibiting foliar symptoms of Eutypa dieback was rated using a 0-to-100\% scale; and (ii) the severity of foliar symptoms was based on the amount of stunting of shoots and assessed using a 0-to-5 scale, where $0=$ no symptoms, 1 = slight symptoms ( 1 to $20 \%$ stunting compared with symptomless shoots), $2=$ moderate symptoms (21 to $50 \%$ stunting), $3=$ severe symptoms (51 to $80 \%$ stunting), $4=$ very severe symptoms ( 81 to $99 \%$ stunting, and $5=$ dead (100\% stunting) (Fig. 1). Based on these records, disease incidence (\%) was defined as the percentage of all vines in the trial block exhibiting foliar symptoms at any level (disease rating $\geq 1$ ). Disease prevalence was defined as the mean percentage of canopy in each trial block exhibiting foliar symptoms. Assessments between 1999 and 2002 were performed by the same person, and assessments between 2003 and 2004 were performed by another person.

Foliar symptom data, used to define parameters depicting changes in Eutypa dieback intensity over time, were divided into four subsets. (i) The first subset included all vines that exhibited any symptoms in year ${ }_{i}$ but were symptomless in the previous year $\left(\right.$ year $\left._{i-1}\right)$. The incidence of vines with new symptoms was determined by dividing the number of vines in this group by the total number of vines assessed in each vineyard. (ii) The second subset included all vines that exhibited any symptoms in year ${ }_{i}$ but were symptomless in the following year $\left(\right.$ year $\left._{i+1}\right)$. The incidence of recovered vines was determined by dividing the number of vines in this group by the total number of vines sampled in each vineyard. (iii) The third subset included only symptomatic vines, and disease prevalence was the mean percentage of canopy expressing symptoms. (iv) The fourth subset included only vines having a severity rating $\geq 3$, and the incidence of vines with severe symptoms was determined by dividing the number of vines in this group by the total number of vines sampled in each vineyard.

Data analysis. Attempts were made to determine coincidence between climatic variables and the disease parameters indicated above. First, coincidence between rain quantity (in millimeters) or the number of rain events (rain greater than 1, 2, 4, 5, or $10 \mathrm{~mm}$ ) in winter (June and July) of year ${ }_{i-1}$ and the incidence of new foliar symptoms in year ${ }_{i}$ was analyzed. Data from Eden Valley and Coonawarra were analyzed separately at first, then attempts were made to identify quantitative relationships that encompassed both sites.

For symptom recovery, two hypotheses were tested. The first related the reduction in disease incidence between year $_{\mathrm{i}}$ and year $_{i+1}$ to pathogen mortality or impairment. As E. lata colonizes the host tissue, it is protected from the direct effects of ambient humidity and irradiation. If pathogen mortality or impairment does occur, this may result from extreme heat or cold. Thus, attempts were made to find coincidence between symptom recovery and parameters reflecting low temperatures in the winter between year ${ }_{i}$ and year ${ }_{i+1}$, or high temperatures in the summer of year. $_{i}$. For low temperatures, daily, weekly, or monthly mean or minimum temperatures and the number of days with a mean or minimum temperature of below 10,8 , or $6^{\circ} \mathrm{C}$ were used. For high temperatures, daily, weekly, or monthly mean or maximum temperatures and the number of days with mean or maximum temperatures greater than 30,34 , or $38^{\circ} \mathrm{C}$ were used. The second hypothesis was that recovery resulted from springtime environmental conditions that either favored rapid shoot growth, allowing growing shoots to recover from the effect of toxins produced by the pathogen, or were not conducive to production of toxins by E. lata. To test these hypotheses, attempts were made to find coincidence between minimum, maximum, or average daily temperatures in the spring, or accumulated temperature in terms of degree-days (base 0) for these variables and recovery of infected vines in year ${ }_{i+1}$. Weekly, monthly, and 2-, 3-, or 4-month averages for the period between 1 August and 30 November of year ${ }_{i}$ were used in the analyses.

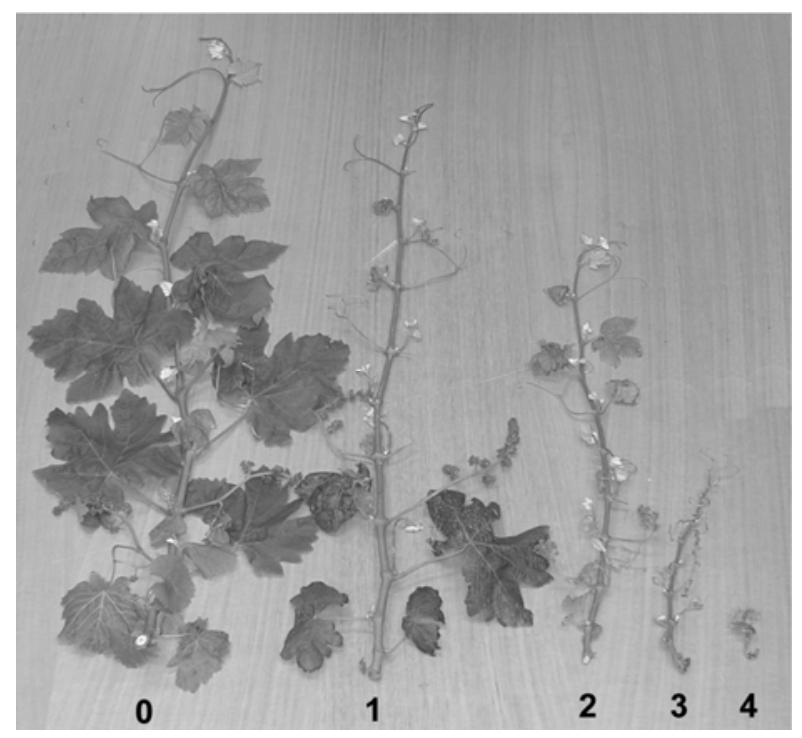

Fig. 1. Visual scale for foliar symptom assessment of Eutypa dieback caused by Eutypa lata, based on the amount of stunting of shoots; $0=$ no symptoms, $1=1$ to $20 \%$ stunting compared with symptomless shoots, $2=21$ to $50 \%$ stunting, $3=51$ to $80 \%$ stunting, and $4=81$ to $99 \%$ stunting. 
The final hypothesis was that disease prevalence and the incidence of vines with severe disease symptoms was related to the production and transport of toxins of E. lata, both of which presumably are influenced by the environment. Environmental variables considered in these analyses were the number of rainy days, accumulated rain quantity (in millimeters), and various temperature variables (minimum, maximum, or mean temperatures or accumulated temperature in terms of degree-days [base 0] for these variables) in late winter and spring. Vines were not irrigated during any of these periods; hence, this did not influence moisture availability. Weekly, monthly, and 2-, 3-, or 4-month averages for
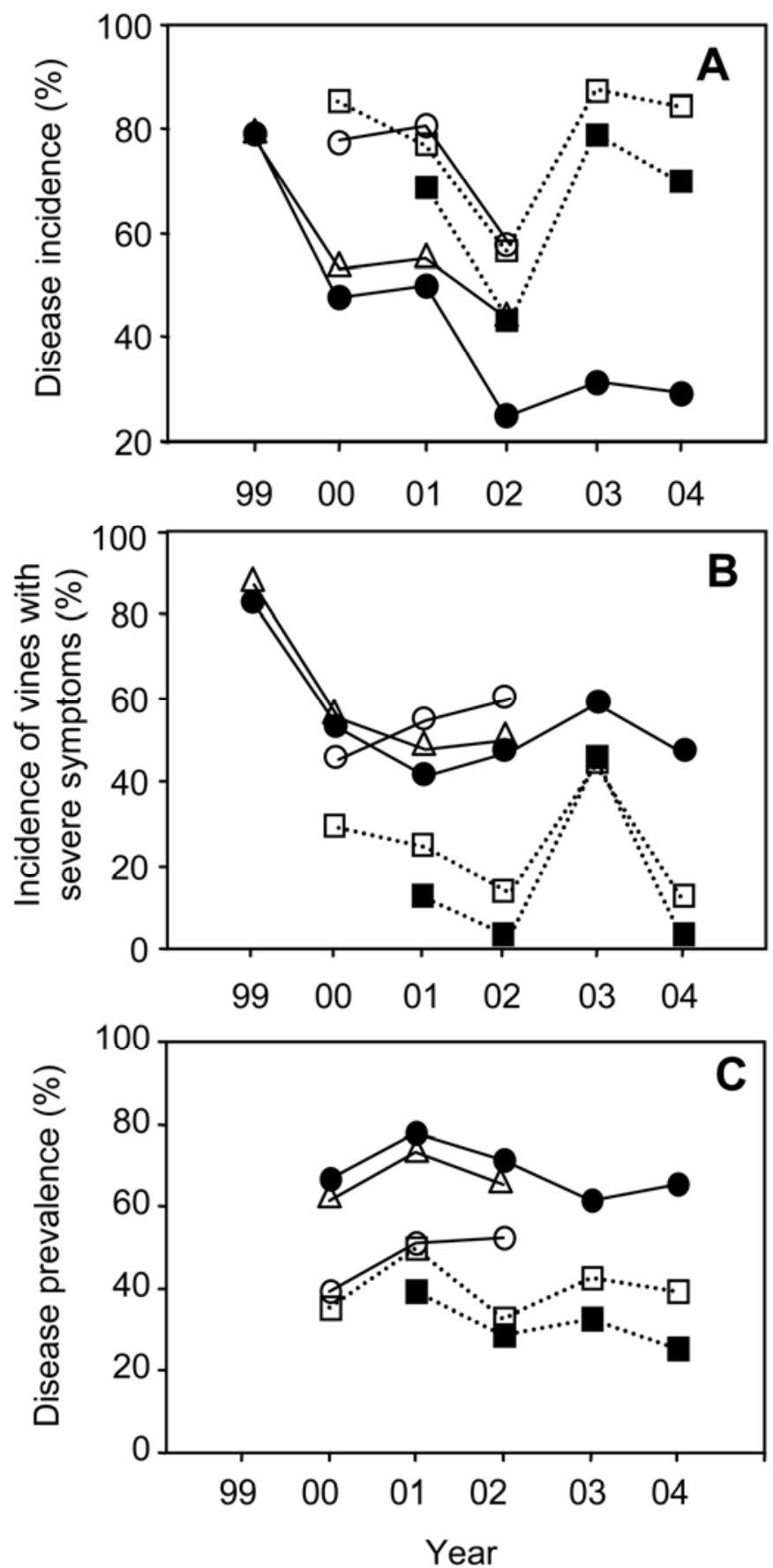

Fig. 2. A, Incidence of foliar symptoms of Eutypa dieback (rating $\geq 1$ ), B, incidence of foliar symptoms (rating $\geq 3$ ), and $\mathbf{C}$, prevalence of foliar symptoms $(\%)$ for all vines in the two vineyards inspected in the Eden Valley (dashed lines, EV1 $=\square$ and EV2 = ) and three vineyards inspected in Coonawarra (solid lines, $\mathrm{C} 1=\mathrm{O}, \mathrm{C} 2=\triangle$, and C3 $=\mathbf{0}$ ) in the years 1999 to 2004. C, Standard error values for disease prevalence within vineyards ranged from 1.4 to $3.4 \%$. the period between 1 August and 30 November of year $r_{i}$ were used in the analysis.

Climate data were imported into Microsoft Excel XP and statistical analyses were performed with JMP software (release 5.0; SAS Institute, Cary, NC). Different regression tests were computed, including simple (linear and nonlinear), multiple, stepwise, and piecewise regressions. Equations were evaluated based on the significance of the estimated parameters, the mean square error, and the coefficient of determination. Analysis of variance and covariance tests were used when appropriate. Only statistically significant relationships are presented in this report; the dependent and independent variables in each of the analyses are indicated in the appropriate Results sections.

\section{RESULTS}

Relationships between climatic factors and symptom expression. The expression of foliar symptoms of Eutypa dieback varied from year to year. Similar trends generally were observed among vineyards, although differences were evident between regions. For example, disease incidence decreased by 10 to $30 \%$ in all vineyards between 2001 and 2002; however, between 2002 and 2003, it increased again by 30 to $40 \%$ in the Eden Valley vineyards but by only $10 \%$ in the Coonawarra vineyards (Fig. $2 \mathrm{~A}$ ). The incidence of vines showing severe symptoms (a foliar symptom rating of greater than 3 ) also varied from year to year in a manner similar to disease incidence; however, there was less variation in disease prevalence from year to year (Fig. 2B and C).

In the first subset defined for parameters of Eutypa dieback intensity, most vines displaying foliar symptoms for the first time exhibited low or moderate severity in the first year in which symptoms were recorded. For example, after recording symptoms for 5 years in vineyard C3 and 3 years in vineyard EV2, 82 and $88 \%$ of the vines displaying symptoms for the first time were placed in severity categories 1 or 2 . An increase in the incidence of vines displaying new symptoms was associated with the number of rain events equal to or in excess of $4 \mathrm{~mm}$ in the previous winter around the time of pruning (Fig. 3), but not with any other rain variables.

The majority of recovered vines (in year ${ }_{i+1}$ ) in the second subset exhibited slight or moderate symptom severity in the previous year. In the years for which recovery was assessed in vineyards $\mathrm{C} 3$ and EV2, 83 and $81 \%$ of the vines included in this category

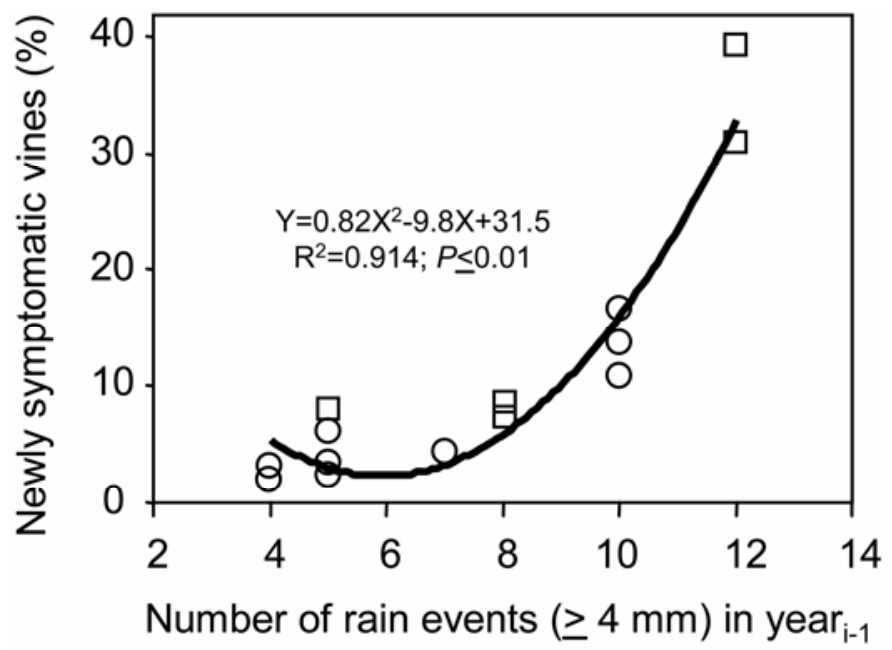

Fig. 3. Relationship between the incidence of newly symptomatic vines (vines that exhibited Eutypa dieback symptoms in year $_{i}$ but were symptomless in year $\left._{i-1}\right)$ and the number of rain events $(\geq 4 \mathrm{~mm})$ in year ${ }_{i-1}$ in Coonawarra $(O)$ and Eden Valley $(\square)$. For Eden Valley, rainfall events were included for the period between 8 June and 8 July and, for Coonawarra, between 20 June and 20 July. 
were rated in severity grade 1 or 2 in year $_{i}$, respectively. No relationships were found between the variables depicting extreme temperature and recovery. However, higher spring temperatures were related to an increase in recovery in year $_{i+1}$. Similar trends were observed in both regions (Fig. 4).

Disease prevalence and the incidence of severe foliar symptoms in the third and fourth subsets were related to the spring climate in year $_{\mathrm{i}}$. For each vineyard, disease prevalence decreased by $0.06 \%$ with each degree-day increase during October and November $\left(r^{2}=0.92\right)$. Differences in disease prevalence among vineyards were significant $(P<0.0001)$ and vineyards in Coonawarra were more diseased than those in the Eden Valley (Fig. 5). The relationship between the incidence of severe symptoms (rating $>$ 3 ) and the quantity of rainfall in October is shown in Figure 6 $\left(r^{2}=0.66\right)$. The highest incidence of severe foliar symptoms occurred when there was approximately $27 \mathrm{~mm}$ of rain in October. When the quantity of rain in October was more or less than $27 \mathrm{~mm}$, the incidence of severe Eutypa dieback symptoms decreased gradually. In vineyards with the most rain $(70 \mathrm{~mm})$, the incidence of severe symptoms was $35 \%$, as opposed to $65 \%$ in those with $27 \mathrm{~mm}$. However, when rain quantity in October was $3.4 \mathrm{~mm}$ or less, no vines exhibited severe foliar symptoms (Fig. 6).

A conceptual model for symptom expression. A conceptual model was developed from these data to predict the incidence of vines displaying foliar symptoms of Eutypa dieback in the current season. According to the model, disease incidence in the current year $\left(D I_{i}\right)$ is the outcome of the previous year's incidence $\left(D I_{i-1}\right)$ plus the incidence of new symptoms resulting from the previous winter $\left(N S_{i-1}\right)$ minus recovery, which occurs in the current spring $\left(R_{i}\right)$, according to the formula $D I_{i}=D I_{i-1}+N S_{i-1}-R_{i}$.

The incidence of vines with new symptoms in the current season was estimated using the regression equation presented in Figure 3: $N S_{i}=31.5-9.8 \times R a_{i-1}+0.82 \times R a_{i-1}^{2}$; where $R a_{i-1}=$ number of rain events $\geq 4 \mathrm{~mm}$ in the winter of year ${ }_{i-1}$. The incidence of recovered vines was estimated using the regression equations presented in Figure 4. For Eden Valley, $R_{i}=0.111 \times D D_{i}-$ 133.1 and, for Coonawarra, $R_{i}=0.097 \times D D_{i}-144.5$, where $D D_{i}=$ accumulated degree days calculated using maximal spring temperature records, with base 0 . The periods for accumulating rain events or degree-days are indicated in Figures 3 and 4,

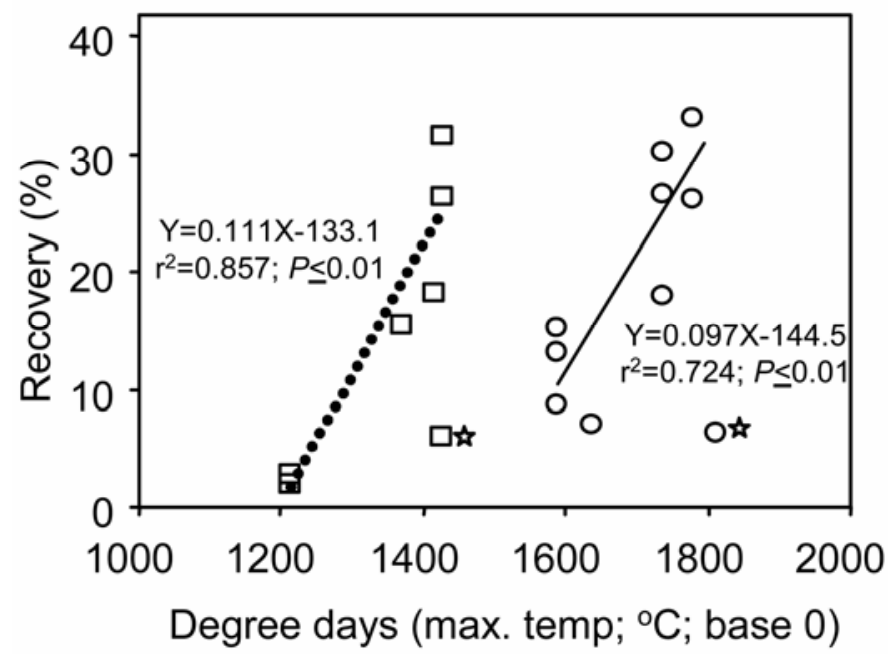

Fig. 4. Relationship between the incidence of vines which recovered from foliar symptoms of Eutypa dieback (i.e., vines that exhibited foliar symptoms

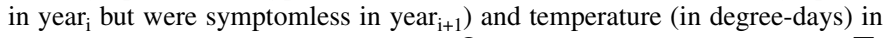
the spring of year ${ }_{i+1}$ in Coonawarra $(\bigcirc$, solid line) and Eden Valley $(\square$, dashed line). For Coonawarra, degree-days were accumulated from September to November and for Eden Valley from August to October. By using a standard deviation of 4 as a threshold for selecting outliers (17), data points accompanied by asterisks were considered as outliers and were excluded from regression analyses. respectively. Data recorded in both regions were used to verify the model; the number of runs for each vineyard varied according to the number of assessment years. Input data used to validate the model were the disease incidence recorded in the first year of assessment in each vineyard, and winter rains and spring temperatures in the appropriate periods for each site. For example, vineyard C2 was assessed for the first time in 1999, when incidence of foliar symptoms of Eutypa dieback was $79 \%$. Based on the above equations, the expected incidence of new symptoms in 2000 was $5 \%$, and $29 \%$ of symptomatic vines were expected to recover. Thus, the predicted incidence of Eutypa dieback for 2000 was $56 \%$. This value then was used as the basis for predicting disease incidence in 2001 (61\%), which was used as the basis for estimating disease incidence in 2002 (34\%). This procedure was repeated for each vineyard included in the study. Predicted incidences then were compared with observed values in each vineyard (Fig. 7). The data points were randomly scattered around the theoretical 1:1 line which represents a perfect coincidence between predicted and observed values. The intercept of the regression equation describing the fit between predicted and observed values $(-0.8 \%)$ did not differ significantly $(P=0.05)$

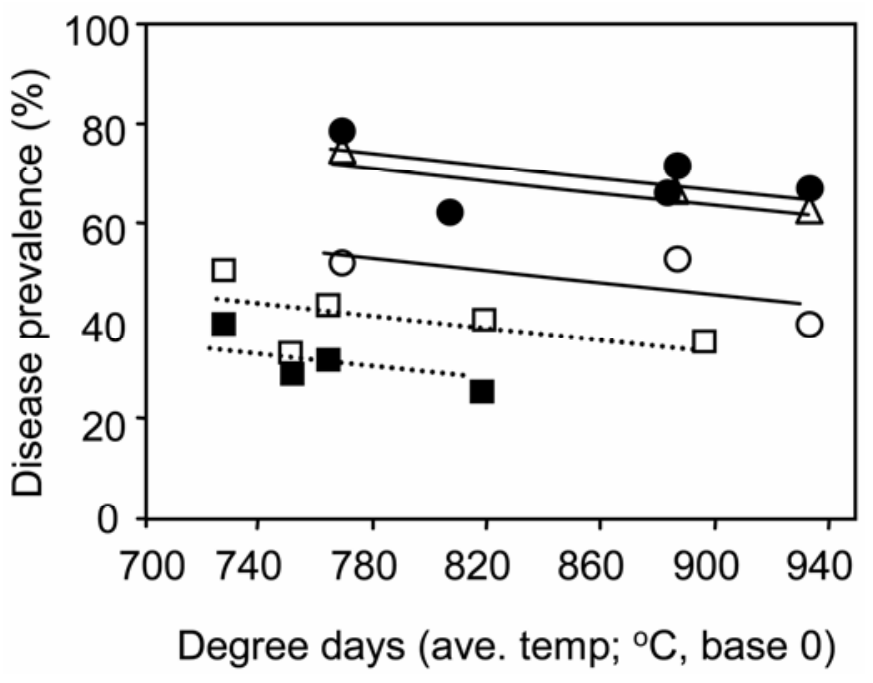

Fig. 5. Relationship between disease prevalence (i.e., the mean percentage of canopy expressing foliar symptoms) and spring temperature (degree days, October and November) for two vineyards in Eden Valley (dashed lines, $\mathrm{EV} 1=\square$ and EV2 $=\mathbf{\square}$ ) and three vineyards in Coonawarra (solid lines, $\mathrm{C} 1=$ $\mathrm{O}, \mathrm{C} 2=\triangle$, and $\mathrm{C} 3=\mathbf{O})$.

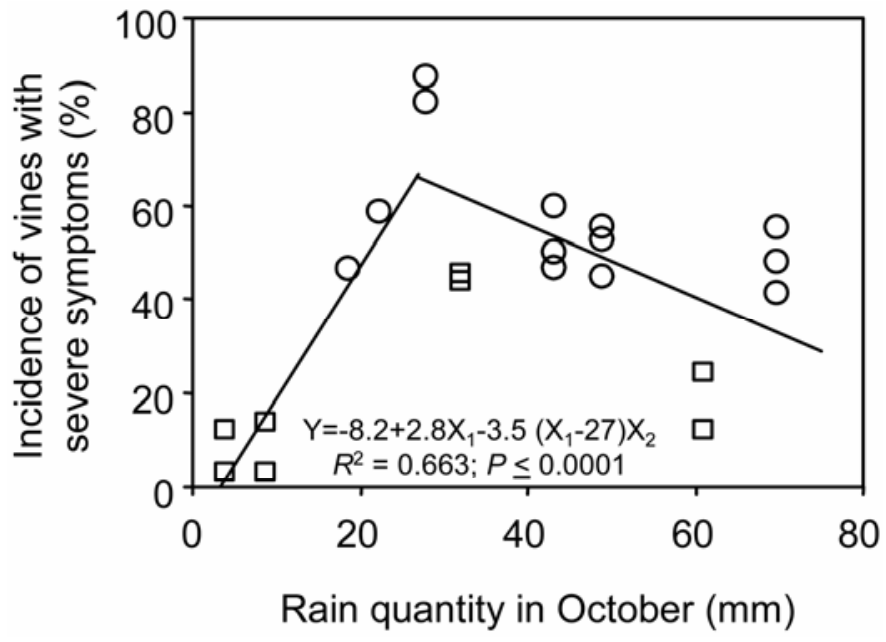

Fig. 6. Relationship between the incidence of vines with severe foliar symptoms of Eutypa dieback (rating $\geq 3$ ) and the quantity of rain in October in Eden Valley $(\square)$ and Coonawarra $(\bigcirc)$. 
from 0 and the slope (1.01) did not differ significantly $(P=0.05)$ from 1. Zero and one represent the intercept and the slope of the 1:1 line. The regression equation was significant at $P<0.0001$ and the coefficient of determination $\left(r^{2}\right)$ was 0.799 .

\section{DISCUSSION}

Here, we confirmed previous reports that the incidence and severity of foliar symptoms of Eutypa dieback vary from year to year $(2,8,9)$, and attempted to identify the causes underlying such variation. Trends in symptom variation were similar within geographic regions, which implies that the annual variation in the severity of foliar symptoms of Eutypa dieback is more likely to be caused by climatic factors than by vineyard management practices, given that these practices, including the time and method of pruning and type of irrigation system, differed between sites within a region.

A number of possible relationships between climate and symptom expression were identified. An increase in symptom expression between years appeared to be associated with increased winter rainfall over a period of a month during June and July in year $_{i-1}$. Although vines were often mechanically prepruned in June and July, hand pruning in August and September in most vineyards would have removed any newly infected wood and exposed wounds to further infection in late winter and spring. Furthermore, foliar symptoms have been induced between 1 and 3 years after inoculating vines in the field with mycelial plugs (12); however, a minimum delay of 3 years has been reported when using ascospore inoculum $(5,21)$. Therefore increased symptom expression in year ${ }_{i}$ is not likely to be linked to new infections in year $_{\mathrm{i}-1}$ due to increased rainfall (3). A possible explanation for this relationship is that high rainfall in this period may be conducive to the production of toxic metabolites in vines that are already infected with the pathogen, whereas low rainfall may promote endophytic survival of the fungus but not toxin production. This could allow toxins to accumulate in the vine during favorable winter conditions and be transported to the foliage as the sap starts to flow in spring. Further investigation is required to clarify this relationship.

Decreases in disease incidence and prevalence were related to increased temperature in spring. Vines grow more vigorously in warmer conditions, which could reduce the ability of fungal toxins to reach the foliage, and increased amount of foliage may

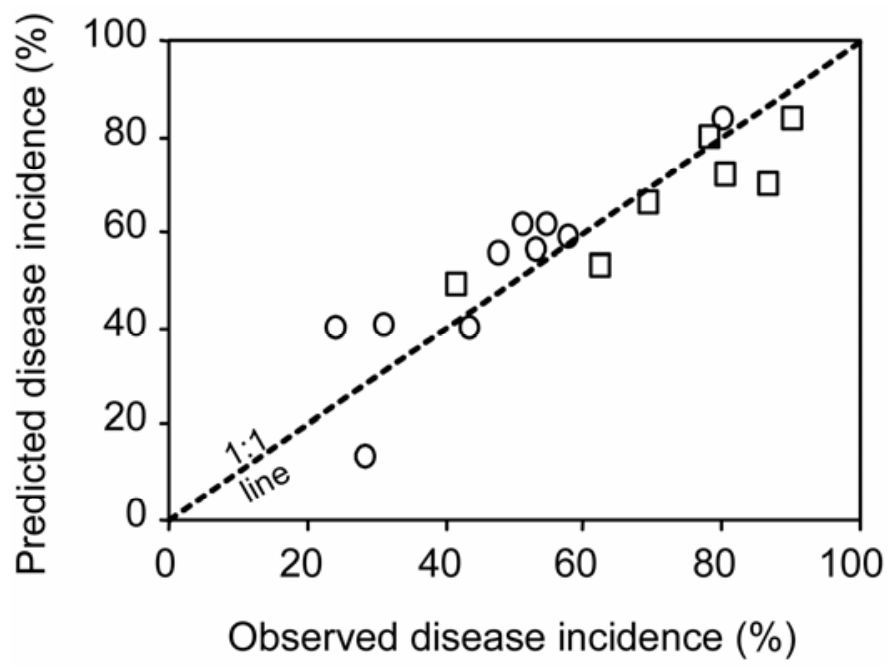

Fig. 7. Verification of the model developed for predicting the incidence of foliar symptoms of Eutypa dieback caused by Eutypa lata based on initial symptoms and climate. The model was run with data recorded in Eden Valley $(\square)$ and Coonawarra $(\bigcirc)$. The 1:1 line is a theoretical line presenting a perfect coincidence between predicted and observed values. reduce the effective toxin concentration. Alternatively, the production of toxins by $E$. lata may be reduced under warmer conditions; however, further research into the effects of temperature on toxin production would be required to confirm this. It is likely that a combination of these factors may explain the relationship.

Another relationship observed in this study involved the effect of October rain on severe disease incidence of Eutypa dieback. A complex interaction between the host and pathogen may exist. A reduction in disease incidence when moisture is readily available possibly may be due to toxin dilution or improved translocation of water to the foliage. A reduction of disease incidence during periods when little moisture is available possibly may be due to reduced toxin production due to water stress on the fungus or limited water movement for transport of toxins throughout the vine.

Mahoney et al. (10) suggested that foliar symptoms are caused by toxic metabolites reacting at the point of production, disrupting the vascular structure and inhibiting transport of nutrients, rather than being translocated to tissues that exhibit symptoms $(13,21)$. This would imply that toxin production and, hence, the extent of foliar symptoms is more likely to be influenced by climate than by toxin movement.

A conceptual model was developed based on relationships identified in this study. The model has the potential to predict the incidence of foliar symptoms of Eutypa dieback in any given season and, hence, could be used to predict yield or to optimize disease management strategies. However, it is important to note that the model must be tested on an independent set of data in order to validate it.

In this study, we identified a number of relationships linking the severity and incidence of foliar symptoms of Eutypa dieback to climatic variables and suggested a number of theories to explain them. However, the relationships may be coincidental and need to be substantiated by experimentation. Such experiments could be carried out initially using rooted vine cuttings in the glasshouse or growth room under controlled moisture or temperature conditions (20). Field trials also could be conducted on vines subjected to deficit irrigation systems to explore the effect of water stress on infection and disease progress over several years. The observations made in this study also highlight the need for basic research to be conducted in the laboratory in order to enhance our understanding of pathogen biology and improve disease management.

Continued monitoring, over 5 to 10 years, of the vineyards assessed in this study, of vineyards in other grape-growing regions, and of different cultivars will allow us to confirm and refine the conceptual model which predicts the potential incidence of Eutypa dieback foliar symptoms. Information from these experiments then could be incorporated into an integrated pest management system to suppress Eutypa dieback symptoms. When combined with current management strategies of wound protection, timing of pruning, sanitation, and removal of infected wood (6), this could maximize the productivity, profitability, and longevity of grapevines affected by Eutypa dieback.

\section{ACKNOWLEDGMENTS}

This research was supported by the Commonwealth Cooperative Research Centre Program and conducted through the CRC for Viticulture with support from Australia's grape growers and winemakers through their investment body, the Grape and Wine Research and Development Corporation, with matching funds from the Federal Government. We thank each of the vineyard managers for allowing us to monitor vines and for providing vineyard records and climate data for analysis.

\section{LITERATURE CITED}

1. Amborabé, B. E., Octave, S., and Roblin, G. 2005. Influence of temperature and nutritional requirements for mycelial growth of Eutypa lata, a vineyard pathogenic fungus. Curr. Biol. 328:263-270. 
2. Butterworth, S. C., Jordan, S. A., and Schilder, A. M. C. 2005. Eutypa dieback: Disease progress and losses in 'Concord' grapes. Phytopathol. Mediterr. 44:106.

3. Carter, M. V. 1957. Eutypa armeniacae Hansf. \& Carter, sp. nov., an airborne vascular pathogen of Prunus armeniacae L. in southern Australia. Aust. J. Bot. 5:21-35.

4. Carter, M. V. 1960. Further studies on Eutypa armeniacae Hansf. \& Carter. Aust. J. Agric. Res. 11:498-504.

5. Carter, M. V. 1978. Eutypa dieback ("Dying Arm") disease of vinesprogress towards control. Aust. Grapegrow. Winemaker 172:27-28.

6. Carter, M. V. 1991. The status of Eutypa lata as a pathogen. Int. Mycol. Inst. Phytopathol. Pap. No. 32.

7. Chapuis, L., Richard, L., and Dubos, B. 1998. Variation in susceptibility of grapevine pruning wound to infection by Eutypa lata in south-western France. Plant Pathol. 47:463-472.

8. Creaser, M., and Wicks, T. 2001. Yearly variation in Eutypa dieback symptoms and the relationship to grapevine yield. Aust. N. Z. Grapegrow. Winemaker 452:50-52.

9. Dumot, V., Ménard, E., Courlit, Y., Ouvrié, M., Desaché, F., Boursier, N., David, S., Dubos, B., and Larignon, P. 2004. Eutypa canker in the Charentes region: Results of a 10-year study on Ugni blanc. Phytoma 568:4-7.

10. Mahoney, N., Molyneux, R. J., Smith, L. R., Schoch, T. K., Rolshausen, P. E., and Gubler, W. D. 2005. Dying-arm disease in grapevines: Diagnosis of infection with Eutypa lata by metabolite analysis. J Agric. Food Chem. 53:8148-8155.

11. Moller, W. J., and Carter, M. V. 1965. Production and dispersal of ascospores in Eutypa armeniacae. Aust. J. Biol. Sci. 18:67-80.

12. Moller, W. J., and Kasimatis, A. N. 1978. Dieback of grapevines caused by Eutypa armeniacae. Plant Dis. Rep. 62:254-258.

13. Moller, W. J., and Kasimatis, A. N. 1981. Further evidence that Eutypa armeniacae - not Phomopsis viticola - incites dead arm symptoms on grape. Plant Dis. 65:429-431.

14. Munkvold, G. P., Duthie, J. A., and Marois, J. J. 1994. Reductions in yield and vegetative growth of grapevines due to Eutypa dieback. Phytopathology 84:186-192.

15. Munkvold, G. P., and Marois, J. J. 1995. Factors associated with variation in susceptibility of grapevine pruning wounds to infection by Eutypa lata. Phytopathology 85:249-256.

16. Muramendiaraz, A., Iturritxa, E., and Legorburu, F. J. 2006. Foliar symptoms of Eutypa dieback are consistent over years and vineyards. Pages 69-70 in: Proc. Fifth Int. Workshop Grapevine Trunk Dis. University of California, Davis.

17. Neter, J., Wasserman, W., and Kutner, M. H. 1985. Applied Linear Statistical Models. R. D. Irwin, ed. Homewood, IL.

18. Ramos, D. E., Moller, W. J., and English, H. 1975. Production and dispersal of ascospores of Eutypa armeniacae in California. Phytopathology 65:1364-1371.

19. Siebert, J. B. 2001. Eutypa: The economic toll on vineyards. Wines Vines April:50-56.

20. Sosnowski, M., Lardner, R., Wicks, T., and Scott, E. 2007. The influence of grapevine cultivar and isolate of Eutypa lata on wood and foliar symptoms. Plant Dis. 91:924-931.

21. Tey-Rulh, P., Philippe, I., Renaud, J. M., Tsoupras, G., De Angelis, P., Fallot, J., and Tabacchi, R. 1991. Eutypine, a phytotoxin produced by Eutypa lata the causal agent of dying-arm disease of grapevine. Phytochemistry 30:471-473.

22. Trese, A. T., Burton, C. L., and Ramsdell, D. C. 1980. Eutypa armeniacae in Michigan vineyards: Ascospore production and survival, host infection, and fungal growth at low temperatures. Phytopathology 70:788-793.

23. Wicks, T., and Davies, K. 1999. The effect of Eutypa on grapevine yield. Aust. Grapegrow. Winemaker 426a:15-16. 